\title{
RECENT RESEARCH IN SOUTHEAST CAPE YORK PENINSULA: NURRABULLGIN AND MORDOR CAVE
}

\author{
BRUNO DAVID
}

\begin{abstract}
This paper briefly reports on archaeological investigations undertaken in SE Cape York Peninsula by the author in 1991. In particular, it presents initial radiocarbon results from Mordor Cave and Nurrabullgin 1 and introduces these sites in the context of broader research questions.
\end{abstract}

\section{Introduction}

One of the key avenues of enquiry available to archaeologists investigating the dynamics of socio-cultural systems concerns changes in the structure of past systems. By structure I not only refer to the internal differentiation of individual systems, and to the particular nature of the organisational principles by which component parts are linked; I refer also to the articulation of systems within a broader, inter-regional dynamic. How do the different regional archaeological signatures from any given point in time relate to each other? How does the archaeological record change through space as one retreats from point $\mathrm{X}$ for a given time in prehistory? Do archaeological 'signatures' represent internally coherent archaeological systems or do they possess variations upon themes which vary through time and space? Are reportedly 'synchronous' changes truly synchronous across different sites or do they in reality represent changes which have taken place at various points in time over a bounded time-frame? Can we identify major changes in the configuration of inter-regional similarities and differences through time? It is particularly with respect to the last question that the research leading to the present paper is geared.

In 1987 the author began a long-term project to document the distribution of rock art forms through a broad section of southeast Cape York Peninsula. Other researchers have, and continue to, also investigate the rock art of other regions within southeast Cape York Peninsula - Walsh (1988) for Princess Charlotte Bay and the Flinders Group, Flood (1987) in the Koolburra Plateau, Cole (1990) at Jowalbinna, Trezise (1971) and Morwood (1989) in Quinkan Country, and Clegg (1978) at Bare Hill. Consequently my aims have been to concentrate on areas where rock art has not been previously investigated - principally Chillagoe (David \& David, 1988), the Mitchell-Palmer (David, in press a), Bonny Glen (David 1991a) and Mt. Mulligan (David 1991b). Together, the various research projects, past and present, have resulted in a near-continuous investigation of rock art spanning the region from Princess Charlotte Bay to Chillagoe.

The aims of the current research have been to order the accumulated data into regional sequences to enable an investigation of where and when particular rock art forms have emerged. Once this is achieved, the spatial distribution of rock art forms through time can be investigated. It is anticipated that the resulting patterns will shed light on the structure of, and changes in, patterns of inter-regional interaction and other demographic variables through time (this is not to say, however, that we can pin-point what the social correlates of particular rock art distributions were). Consequently the 1991 field season in SE Cape York Peninsula was aimed at recording further rock art from two regions - Mt. Mulligan and the Mitchell-Palmer limestone belt - and to undertake excavations to try to shed further light on the antiquity of the rock art from each region.

This paper will only be concerned with the excavations, and will report on fieldwork undertaken during the 1991 field season rather than try to present fieldwork results in light of the research frameworks described above. Three sites were excavated and in each case soundings were located immediately underneath painted panels in the hope that in situ pigments would be retrieved, their stratigraphic location thereby dating the antiquity of painting events. Naturally, it is possible that in situ pigments resulted from activities other than rock art, but the locations of the excavated pits maximised the likelihood that the excavated pigments relate directly to the on-wall paintings. All excavations followed the Johnson (1979) method of bucket spits following the natural stratigraphy, with all cultural materials noted in situ being plotted in three dimensions and bagged separately. All other materials were sieved in a $3 \mathrm{~mm}$ wire-mesh sieve.

\section{The Mitchell-Palmer Limestone Belt}

The Mitchell-Palmer limestone belt consists of a $60 \mathrm{~km}$ long and $5 \mathrm{~km}$ wide belt of karst towers. Caves are abundant throughout the limestone, two of which were excavated by the author in 1989 (Hearth Cave and Mitchell River Cave [David 1991c]). Mordor Cave, located in the Mordor North Tower, was excavated by the author in 1991.

Mordor Cave is a large limestone cave with an uneven rocky floor. The entrance to the cave involves a moderate climb up boulder-strewn pediments and a subsequent steep descent onto a flat floor located near the back wall. It is here that the only occurrence of soft, ashy deposits is located. Against the cave wall there are many figurative paintings and hand stencils. A number of collapses leading to deep caves occur at both ends of the cave. Two edge-ground axes were found in the collapses which can be reached by a short walk through pitch-black corridors in the rock.

Two test excavations were undertaken in the soft deposits. Square E 18 consists of a single $50 \mathrm{~cm} \times 50 \mathrm{~cm}$ 
pit located near the centre of the soft deposits where sediments appear to be deepest in this part of the site. The main excavation was undertaken $3.5 \mathrm{~m}$ from $\mathrm{E} 18$ and consists of squares $\mathrm{G} 10, \mathrm{H} 10, \mathrm{H} 11$ and 110 . Square H10 was initially selected for excavation because it was located in what appeared to be the deepest part of the site. Both excavations were well stratified (Figure 1), containing numerous layers, each of which was rich in ash/charcoal, organic materials and cultural deposits. and a large number of partly burnt pandanus nuts, five of which were located immediately on top of the sheet of cut bark. Curiously, most of these lay in an approximately $70 \mathrm{~cm}$-thick layer consisting almost entirely of bark, twigs and other organic material. This unit (SU 4) had the appearance of an 'instantaneous', anthropogenic event. It was an extremely unusual stratigraphic unit, and was certainly different in internal structure to the grass/bark sleeping mat layers occasionally found in some

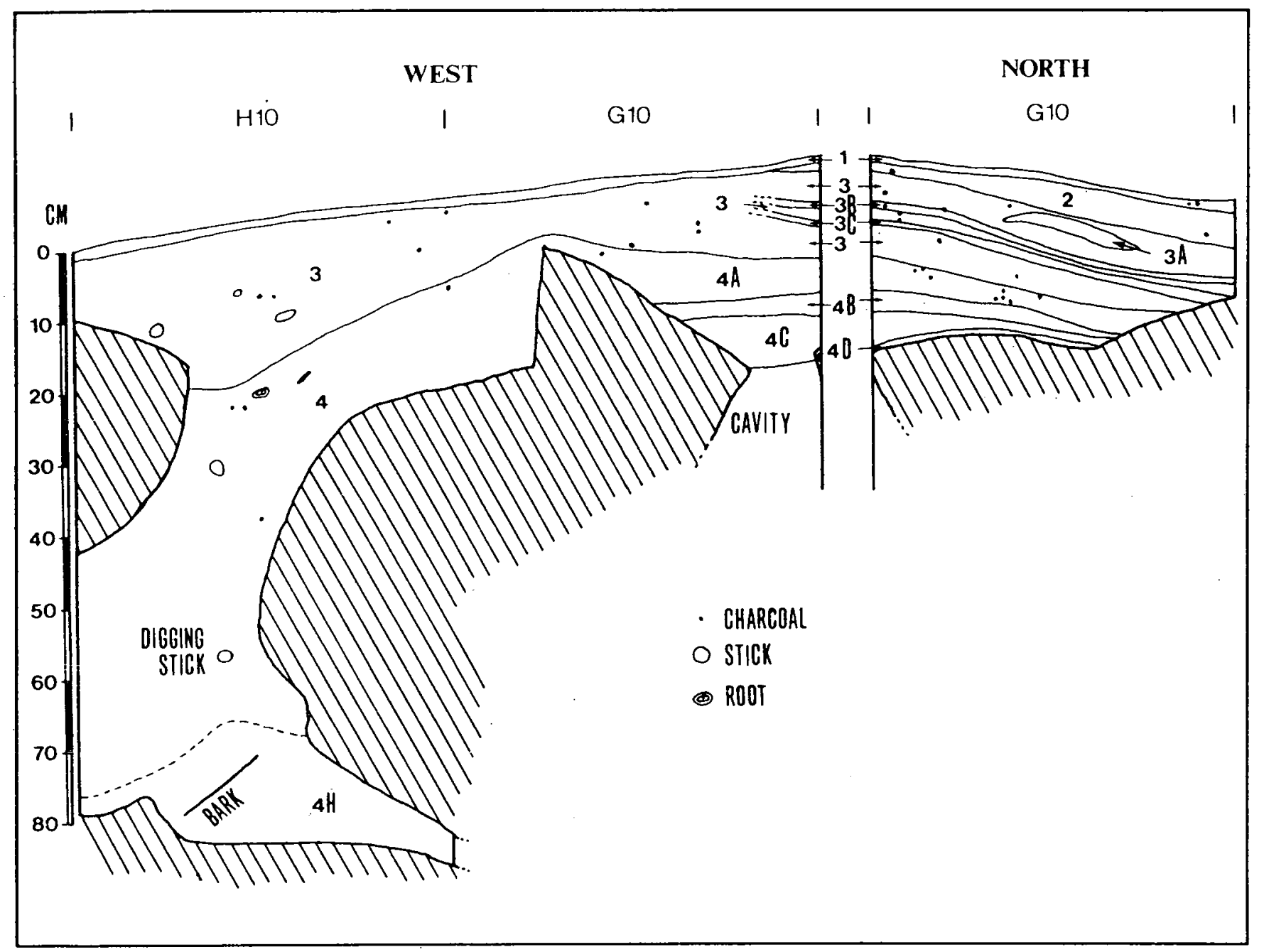

Figure 1: Mondor Cave, West and North Sections, Squares G10 and H10

Sorting of the Mordor Cave material has not been completed, but some indication of the richness of the cultural finds from the site can be gained by the materials obtained in situ. Excavation in both pits went to bedrock, located $20.0 \mathrm{~cm}$ below ground surface in E18, and $114.5 \mathrm{~cm}$ in $H 10$. Fragments of pigment, some of which were use-worn, were identified from both pits. The G-HI squares also contained a number of unexpected items a dingo skeleton (only partly excavated, the rest remaining in the section in unexcavated deposits), a wooden digging stick, a length of wood with a welldefined shaped end (probably a digging stick), a large sheet of cut stringy-baik with numerous clear cut-marks, shelters (e.g. Nara Inlet [Barker, pers. comm.] and Nurrabullgin 1). The organic fraction was not horizontally laid, but consisted of a mixed matrix. Limestone boulders occasionally appeared, and in some places the organic matrix, upon excavation, was revealed to lie immediately upon a void: the stratigraphic unit would suddenly give way to a deep hole below, forming a false floor between boulders. Across most of the excavation, however, the organic matrix lay immediately on top of bedrock. The organic material in SU4 proper, being $42 \mathrm{~cm}$ thick, shows no signs of disintegration in any part of the excavation.

Three radiocarbon dates were obtained from Mordor 
Cave. All samples are on good charcoal samples excavated in situ, and have been ${ }^{13} \mathrm{C}$ adjusted:

$1580 \pm 70 \mathrm{BP}$ (Beta-46090). This dates the base of $\mathrm{E} 18$ (XU7).

$940 \pm 60 B P$ (Beta-46317). This comes from near the digging stick, and is located in XU25 of square $\mathrm{H} 10$ (in SU4, the organic matrix).

$800 \pm 50 B P$ (Beta-46318). This sample is from XU28. It dates the base of square $\mathrm{H} 10$ and the base of the organic matrix (SU4H).

Given the similarity of dates Beta-46317 and 46318, located three excavation units apart but both located within the organic matrix, SU4 is taken to be an archaeologically instantaneous event. This stratigraphic unit can be sub-divided into two main sub-units, SU4 proper (the upper section), consisting of well preserved plant material, and $\mathrm{SU} 4 \mathrm{H}$, consisting of plant matrix which has begun to decompose, probably as a result of its proximity to bedrock, where humidity is higher. Given the presence of large cultural objects and large amounts of food refuse and stone artefacts within SU4, it is also believed to be anthropogenic.

\section{Nurrabullgin}

Nurrabullgin (Mt. Mulligan) is traditional Kuku Djungan country. It is an $18 \mathrm{~km}$-long, $400 \mathrm{~m}$ high table-top mountain with a volcanic base and sandstone capping. Two sites were excavated at Nurrabullgin, one of which is located at the top of the mountain, and the other at its base.

Nurrabullgin Cave is a large sandstone shelter located at the top of the mountain. Excavations at this site have been published elsewhere (David, in press b) and will only briefly be reported here.

Excavation of a single $50 \mathrm{~cm} \times 50 \mathrm{~cm}$ square (M25) revealed an occupational sequence spanning over 37170 years. Cultural materials occur in all XUs to bedrock, with considerable numbers of bones also being present, most of them being carbonised or calcined. All sediments are highly compact and consist mainly of exfoliated cave wall material, charcoal and ash (the latter two contributing to the compaction of sediments). A major increase in deposition rates of all cultural materials is apparent for the mid- to late-Holocene, including the first evidence of use-worn pigments. An extension of the original excavation at Nurrabullgin Cave is needed to shed further light on the nature of occupation at the site, although the presence of fine strata and the total absence of snapped artefacts from the Pleistocene layers may imply intermittent visits by few people in the past rather than frequent use of and heavy treadage in the site.

Nurrabullgin 1 is a medium-sized rhyolite conglomerate shelter located at the base of Nurrabullgin. Surface sediments are very soft and ashy. A pig-rooting area has exposed sub-surface sediments along one end of the shelter, where finely stratified sediments are evident.

Excavation of six $50 \mathrm{~cm} \times 50 \mathrm{~cm}$ squares against the back wall and under a painted panel were undertaken (Figure 2). Sediments are finely stratified, and include a thin organic layer consisting of stringy-bark and other plant materials reminiscent of sleeping mats. A major stratigraphic break takes place below SU2, where disintegrating roof-fall occurs. No cultural materials have been observed below this break. Ochre, stone artefacts, very large numbers of burnt nuts of various species, and large amounts of bone occur at the site, although sorting. of the excavated sediments is not complete. $A{ }^{14} \mathrm{C}$ date of $4110 \pm 70 \mathrm{BP}$ (Beta-45772) has been obtained from the base of cultural deposits.

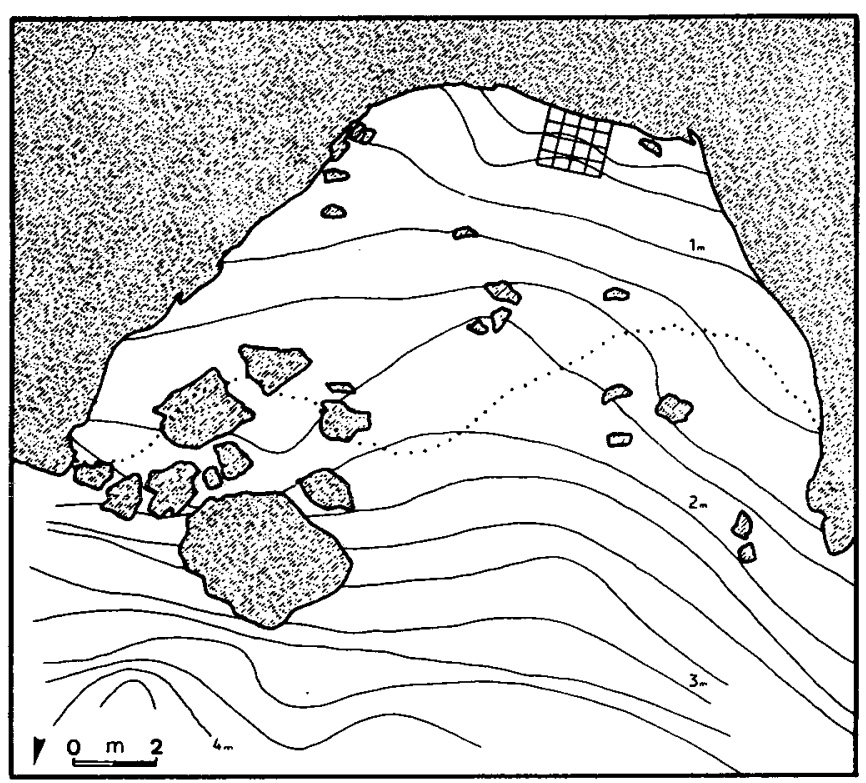

Figure 2: Nurrabullgin 1, site plan; contours in $20 \mathrm{~cm}$ intervals (in metres below site datum). Arrow points to magnetic north.

\section{Conclusions}

The results of the 1991 field season re-enforce previously published archaeological patterns of increase site use during the mid- to late-Holocene. Furthermore, they also re-enforce the previously observed patterning of a late Pleistocene occupation of SE Cape York Peninsula characterised by the creation of relatively homogeneous non-figurative and track peckings, with the emergence of relatively region-specific art 'styles' during the mid- to late-Holocene. One of the problems with this characterisation, however, is its treatment of the Pleistocene (and early Holocene), as a socio-cultural tradition spanning at least 30,000 years of human presence. This tendency gives the Pleistocene and early Holocene an apparent uniformity, presenting early cultural practices in a static mould. Undoubtedly, the early period of occupation in SE Cape York Peninsula, as in Australia in general, witnessed numerous changes not treated adequately by viewing Australian prehistory as a two-fold sequence. Unfortunately, however, our knowledge of the archaeology of early times is very limited, especially when it comes to identifying particular time specific characteristics from individual regions. It is largely for this reason that the dynamics of Pleistocene ant early 
Holocene times has remained largely uninvestigated, and that the early period of occupation is often conveniently lumped into the Pleistocene mode of life.

Having said this, the richness of each of the three sites reported here will hopefully contribute to a broader understanding of the prehistory of the region. Greatly increased information on foraging behaviour (including investigations on the foraging of plant foods) and material culture, as well as on stone technologies and use, rock art and inter-regional relations, will hopefully emerge. In the long term it is anticipated that the various archaeological investigations resulting from this work will be integrated to enable a greater understanding of the various regional prehistories, and better enable an understanding of how these regional scenarios articulate in a broader, interregional prehistory. Coupled with the research of Morwood (1989) and others (e.g. Campbell 1982) in the broader region, it is anticipated that detailed regional prehistories for southeast Cape York Peninsula will soon be formulated.

\section{Acknowledgments}

I would like to thank the Kuku Djungan Aboriginal Corporation (and especially elders John Grainer, Alf Neal and Samuel Wason), Reg and Sherelly Adams, Howard Kingsley and Mr. and Mrs. Wilson for allowing me to undertake archaeological investigations on Kondaparinga, Mt. Mulgrave and Palmerville Stations. Thanks also to Brigid Cassidy, Claire Barron, Claire Cassidy, Bryce Barker, Roger Cribb, Les Hall, Lara Lamb, Lana Little, Rino Randazzo, Bruce White and Phil Wall for their company and assistance in the field. The 1991 field season was partially financed by the A.I.A.T.S.I.S. and the Department of Anthropology, University of Qld., to whom $I$ am also indebted. The radiocarbon dates for Mordor Cave were financed by the Cultural Heritage Division, Department of Environment and Heritage (Brisbane), to whom my thanks are also extended.

\section{References Cited}

Clegg, J. 1978 Mathesis words, Mathesis pictures. Unpublished M.A. (Honours) thesis, University of Sydney, Sydney.
Cole, N. 1990 Rock art of Jowalbinna. Unpublished B.A. (Honours) thesis, James Cook University of North Queensland, Townsville.

David, B. 1991 a Preliminary report on Aboriginal rock art sites on Bonny Glen station, southeast Cape York Peninsula. Unpublished report submitted to Wujal Wujal Community Council, Bloomfield.

David, B. $1991 \mathrm{~b}$ Preliminary archaeological investigations at Mt. Mulligan: rock art and excavations. Unpublished report to A.I.A.T.S.I.S., Canberra.

David, B. 1991c Mitchell River Cave: a late Pleistocene/Holocene archaeological site from north Queensland. A ustralian Aboriginal Studies.

David, B. in press a Rock art of the Mitchell-Palmer limestone belt, north Queensland. In J. MacDonald (ed) (title of book unknown). A.A.P., Canberra.

David, B. in press $b$ Preliminary results from Nurrabullgin Cave: a pre-37170 year old rockshelter from North Queensland. Archaeology in Oceania.

David, B. and David, M. 1988 Rock pictures of the Chillagoe-Mungana limestone belt, north Queensland. Rock Art Research 5(2):147-156.

Flood, J. 1987 Rock art of the Koolburra Plateau, north Queensland. Rock Art Research 4(2):91-126.

Johnson, I. 1979 The getting of data. Unpublished PhD thesis, A.N.U., Canberra.

Morwood, M. 1989 The archaeology of Aboriginal art in southeast Cape York: a research proposal. Rock Art Research 6:71-72.

Trezise, P. 1971 Rock Art of Southeast Cape York. A.I.A:S., Canberra.

Walsh, G. 1988 Cultural Resource Management: Princess Charlotte Bay. Unpublished manuscript, Dept. Environment \& Heritage, Brisbane.

Bruno David

Department of Anthropology \& Sociology The University of Queensland Queensland 4072 